Article

\title{
Toward a Sustainable Future: The Case of the Municipality of Milan
}

\author{
Silvia Ivaldi ${ }^{1, *}$, Francesca Bertè ${ }^{2}$, Sergio Sorgi ${ }^{2}$ and Giuseppe Scaratti ${ }^{3}$ \\ 1 Department of Human and Social Sciences, Università degli Studi di Bergamo, 24129 Bergamo, Italy \\ 2 eQwa, 20100 Milan, Italy; francesca.berte@eqwa.it (F.B.); sergio.sorgi@eqwa.it (S.S.) \\ 3 Department of Psychology, Università Cattolica del Sacro Cuore di Milano, 20123 Milano, Italy; \\ giuseppe.scaratti@unicatt.it \\ * Correspondence: silvia.ivaldi@unibg.it
}

Received: 29 December 2018; Accepted: 1 February 2019; Published: 8 February 2019

check for updates

\begin{abstract}
In the new framework of the Psychology of sustainability and sustainable development, this paper addresses the issue of building socially sustainable processes to develop a better quality of life in an urban context. The aim is to explore and highlight the connection between the acknowledgment of a pluralistic and multi-stakeholder scenario, the entwined implications for sustainability at different levels (personal, social, organizational), and the enhancement of the participatory process of planning for future accomplishments. A case study supported by the Municipality of Milano (Italy) is analyzed with the aim to understand the key issues to improve the well-being of the citizens. The paper describes the context of the experience, highlighting the Delphi approach adopted and the ways applied to involve citizens in urban development policies. Discussion and conclusions address the lesson learnt from the case study, pointing out how to prompt and nurture sharing and knowing opportunities and the specific conditions that can support plural stakeholders' engagement in a sustainable urban future.
\end{abstract}

Keywords: multi-stakeholder collaboration; Inter-organizational; social sustainability; participative projecting; Milano 2046; psychology of sustainability and sustainable development

\section{Introduction}

Social and organizational collective systems are characterized by a huge level of complexity, pluralistic settings, and forms of organization [1]. The possibility of creating value at multiple levels is strictly connected to the effective involvement of multiple stakeholders and the social sustainability of their collaborative participation [2,3]).

Multiple and diverse practitioners, groups, and collective subjects, inside and outside an organization, have to deal with the relational processes of multiple stakeholdership and partnership [4]. The challenge is to cope with multiple professional cultures, interests, objectives, expectations, social and power dynamics, and intra- and inter-organizational pressures [5]. Hence, attempts have been made to explore sustainability in its multiple implications to mobilize various stakeholders to be involved in different strategic processes [6].

Adopting this perspective, the paper addresses the issue of building socially sustainable processes to develop a better quality of life in an urban context. The aim is to explore and highlight the connection between the acknowledgment of a pluralistic and multi-stakeholder scenario, the entwined implications for sustainability at different levels (personal, social, organizational), and the enhancement of participatory processes of planning through gathering and detecting situated and distributed knowledge among people belonging to a common environment. 
This article underlines the methodological aspects that can be adopted for achieving a multi-stakeholder perspective and a sustainable accomplishment of partnership among different persons, groups, and collective subjects. The paper refers to a case from the public sector to highlight potential problems and practical implications with an aim to enhance collective endeavors to achieve sustainability. The case relies on a project (Milano 2046) supported by the Municipality of Milano (Italy) aimed at understanding the key issues for improving the future well-being of the citizens. More specifically, Milano 2046 aims to create a sustainable city by identifying critical issues and investigating the opinions of citizens, experts, and stakeholders on topics related to social cohesion, culture, environment, citizenship and participation rights, personal and public quality of life, and social relationships.

Specifically, the study addresses the following questions:

- How can sharing and knowing processes related to local contingencies, problems, and situations be prompted and nurtured?

- What conditions can create a suitable setting for involving plural stakeholders around the issue of a sustainable urban future?

The paper unfolds as follows: In the second paragraph, we discuss the theoretical framework underlying multi-stakeholdership, sustainability, and participatory processes. In the third paragraph, we present the case's context and the main features of the project at stake; and in the fourth paragraph, we refer to the methods and processes applied in the case study. Finally, we discuss the methodological approach adopted, the implications for the various subjects involved, and suggestions for further research.

\section{Theoretical Framework}

\subsection{Multi-stakeholder Collaboration as A Sustainable Process}

To highlight the connection between stakeholder management policies and the improvement of the decision-making processes, we can rely on a stakeholders' perspective. Although many definitions of stakeholders have been adopted in the literature, the one originally proposed by Freeman [7], which specifies "any group or individual who can affect or be affected by the achievement of the organization's objectives" as a stakeholder, is still widely used today. Freeman developed and formalized the Stakeholder theory within the economic and corporate context [8]. The theory focuses on how companies (and managers) deal with diverse subjects who have different expectations and interests. According to this theory, rather than focusing exclusively on maximizing an economic result, companies should conduct a production activity, with an emphasis on the process, in a way that enables them to ensure a balance between the expectations of their stakeholders. Mid-long term success of a company is from this perspective, therefore, determined by the ability of the management to efficiently use its available resources to comply with these expectations. A stakeholder perspective considers building a model of value creation according to the relations with internal and external stakeholders. This theory assumes a relationship of mutual influence between the company and its internal and external context and presumes that the expectations of those implicated have equal dignity and value. The company should, therefore, be conceived as a system that is not only identifiable with the owners, its employees, its products or its commodities but also composed by the relationship between them in continuous evolution. Enterprises, even when oriented to profit, are institutions characterized by the pursuit of a continuous balance between the economic and social dimension in which the first is dependent on the achievement of the latter.

Acknowledging different stances, interests, and approaches enhance the collaborative interaction among plural subjects and pluralistic contexts, facilitating the development of forms of collective sharing and knowing in situ [9-11] that deal with local contingencies and specific situations [12].

Knowledge sharing between stakeholders is believed to help identify problems and to develop strategies for dealing with complexities [13] and offering solutions to welfare problems [14]. Another 
benefit that can be achieved through the adoption of a stakeholder management system is a general improvement in innovation processes by enabling creative processes that bring an alternative mode of knowledge to the forefront [15] A further advantage of stakeholder involvement is the possibility of creating a greater sense of ownership and simplifying the implementation of the solutions identified [16].

Nevertheless, such a perspective cannot be taken for granted, as it implies that multiple actors, representatives of different contexts and systems (for example, civil society, business, and governmental institutions, trade unions, supply chain partners, customers, clients, and employees), come together to find a common approach to an issue that affects them all [17]. In this direction, different studies and contributions have highlighted the relevant steps and features of a multi-stakeholdership process.

A starting point for the management of a stakeholder system is the identification of relevant stakeholders. The eligible stakeholders who may be involved in the design of the project are identified according to their contribution to the comprehension/definition of the social problem [18] or according to their ability to activate useful resources for its implementation. Another crucial factor is the commitment to be engaged consistently and on an on-going basis. According to these considerations, two types of stakeholders can be distinguished: Core stakeholders and primary/secondary stakeholders. The former ones constitute the working group that will make decisions regarding the goals and execution of the project. The latter ones, while being recognized as playing a primary role, will be involved in a less consistent way, having a consultative rather than a decision-making function [19]. However, not all types of involvement are useful. Critically speaking, stakeholders might be included for purely symbolic reasons or to promote conformity rather than variety. Similarly, the exclusion of relevant stakeholders may damage the project, and it may be necessary to reconsider the composition of the project in response to unexpected events. Some stakeholders, even if not considered relevant, may have a reasonable expectation of being involved, and their exclusion should always be addressed.

Once the stakeholders have been identified, it is necessary to consider the different interaction between the core stakeholders and the primary/secondary stakeholders. Different degrees of stakeholder involvement have been identified, specifically, information, consultation, involvement, and collaboration. At the first stage, the core stakeholders make a commitment to periodically inform primary/secondary stakeholders about the outcomes of their work and the results achieved. This policy relies on one-way communication tools (e.g., announcements, conferences, newsletters). Adopting an information policy presents potential risks in those cases in which the stakeholders judge the results achieved as not satisfying or irrelevant. Moreover, involvement itself can be judged negatively because of its one-way nature, which can damage the image of its promoters. A second possible policy requires core stakeholders to periodically disclose information about their work-as in the information policy-but in this case, they also collect opinions, comments, and suggestions from stakeholders. This policy marks the transition from one-way communication to a more dialogical approach; therefore, it requires the use of tools, such as interviews, focus groups, presentations, or questionnaires. Such an approach is particularly effective when the interaction with stakeholders focuses on a specific topic or issue. The main risk of this approach is that it may raise expectations that cannot be adequately met because of the unfeasibility of implementing the changes needed to comply with the proposed suggestions. The third policy implies the involvement of stakeholders in the decision-making processes, engaging them in the definition of the goals and in the selection of the actions that are going to be taken. Concerning the dialogue policy, it is necessary to consider the involvement of stakeholders in the decision-making process only if the core stakeholders are seriously willing to consider the comments and suggestions regarding their decisions. Finally, through a collaborative policy, the stakeholders are involved both in the decision-making phases and in the implementation phases of the initiatives. For this policy to be implemented, it is necessary to evaluate the willingness of the actors involved to collaborate on an ongoing basis and to establish ad hoc committees or working groups. This entails an assessment of the sustainability of the entire process. 


\subsection{Sustainability as a Multi-Level Fine-Tuning Process}

According to the new framework of the Psychology of sustainability and sustainable development [20-22], we welcome a shift from a sustainability framework that emphasizes the avoidance of actions considered to be detrimental to the economic, social, and ecological environments, to sustainable practices based on prevention and the development of generative resources.

When addressing the issue of sustainability, it is possible to articulate the topic from two main perspectives. The first is the examination of the substantive aspects of the concept related to the definition of sustainability and dimensions that could be considered "within" its boundaries, that is, aspects that should be and should not be included in the concept of sustainability. Sustainability has been traditionally addressed by differentiating between the domains of economy, (social) equity, and ecology, best known as the three Es. Many authors have however proposed to evaluate sustainability as a unified and integrated concept $[6,23,24]$, while others have expanded this classification to consider the individual level as both necessary and desirable [22] The second perspective focuses on the procedural aspects of sustainability, that is, on the means by which social actors achieve their goals. In this sense, sustainability refers to the process of safeguarding and developing human, social, and economic $[25,26]$ and ecological resources.

Galuppo et al. [6] claimed that with regard to substantive aspects, social sustainability means contributing to the internal and external stakeholders' development and growth by achieving several goals, such as equity, well-being, social cohesion and inclusion, and the opportunity for learning and self-development [27]. In terms of procedural aspects, social sustainability requires an organizational commitment towards the stakeholders who should be brought together through new forms of transparent and participative management, communication, and decision-making [28].

Despite these different perspectives and domains, in most contributions, the social sustainability concept appears as a holistic and systemic concept to be handled by exploring the dynamics and interrelationships between different domains and systems of meanings and interests, such as profit versus people or economic performance versus social and human well-being [23,24].

Creating a socially sustainable process requires specific management strategies and capabilities related to the challenge of promoting reflexivity and paradoxical thinking attitudes $[6,29,30]$.

Therefore, stakeholders who are more engaged in the transparent and participative processes can develop more solid—and not merely cosmetic - journey towards social sustainability. The primary purpose of the organization is to serve society; thus, the organization's mission is to serve stakeholders by addressing broader issues of common interest in the present or in the future. The commitment here is towards a new common future, which requires changing the course of action and leads to a rebuilding of new balances and new ways of organizing and living together. While the skeptical and the pragmatic strategies reveal a "cosmetic" or instrumental approach to social sustainability driven by economic concerns and generate only episodic outcomes, the engaged and idealistic perspectives consider social sustainability as a process of creating shared values by balancing not only economic interests but also social and human needs. From this perspective, at stake are both personal, social, and organizational features of sustainability seeking for challenging and common endeavors.

\subsection{Citizens' Involvement in Urban Development Policies}

The growing attention to the stakeholder involvement and collective projecting by policy makers is due to the EU's early Lisbon Strategy of the 2000s, that has launched funding programmes (the most popular in the research field is the Horizon 2020) aimed at promoting the EU as 'the most competitive and dynamic knowledge-based economy in the world, capable of sustainable economic growth with more and better jobs and greater social cohesion [31]. These programmes, which set the guidelines and principles that will guide the allocation of funds in subsequent years, have encouraged network designs and inter-organizational collaborations that entail the active involvement of civil society, research and education institutions, and public sector. The idea underlying these policies is that addressing complex social problems, like the ones the EU is currently facing (economic stagnation, rising unemployment, 
and others), and increasing the chances of success of the initiatives financed, it is necessary to adopt ecological approaches and solutions that would consider the needs and interests of the largest number of social actors (directly or indirectly) affected by its initiatives. In this regard, the EU introduced in its financing programmes a partnership principle, requiring an increased stakeholder involvement by including different actors at local and regional levels, thereby emphasizing a multi-stakeholder and multi-institutional policy framework [14,32].

The three above-mentioned perspectives sound as a trigger for the Milano 2046 project that is based on a multi-stakeholder perspective and the willingness to promote an effective and relevant participatory movement by mobilizing knowledge from different sources.

\section{Multi-stakeholdership: Milano 2046. Birth, Motivations, Choices}

\subsection{The Idea}

The idea of Milano 2046 was developed, for the first time, at the end of May 2017 based on a reflection of the separation between citizens' life and political representatives. The political orientation of Italian voters was clearly underlining the lack of confidence to lead the country in the traditional political way, and this sentiment affected also the city of Milan. If, on the one hand, people were satisfied with the trend of the city, there was, nevertheless, a strong suspicion that this satisfaction should not be attributed to the sharing of the strategic orientation of the government but to its attitude towards leaving the city to deliver its own project without constraints.

To put it over succinctly, the citizens were satisfied because the political system was "lateral and light" rather than because of its strong attitude to imagine, project, and design a sustainable future.

Furthermore, the new orientation of the voters was moving toward policies based on the defense of the identity, reduction of taxes for the richest part of a population, and restitution of pension privileges to the old pensioners. These kinds of policies traditionally foster "individual short-term" behavior.

Finally, people seemed to be insecure and scared about the "other" [33], and they wanted to avoid individual responsibilities. One could argue that the subjective and collective fears, as well as the lack of attitude towards the future, created an attitude to the "now" and the "short-term way of thinking" [34]. What kind of future may be pursued with no future in subjective and intersubjective perceptions? Furthermore, how could people abandon the individual and present requests in order to privilege the future without developing attention to the future itself?

In this light, the first purpose of Milano 2046 was to explore the possibility to develop attention to the future and to facilitate a collective thought for posterity.

Studying the sustainable future of Milan is an innovative and at the same time, a natural decision. Milan is the second most populated Italian city, but in terms of economy and innovation, it has become the first city. Moreover, historically, the city has gone through complex phases but in the last decade, it has experienced a 'rebirth' and a strong growth.

\subsection{Milan: Specific Situation and Contingencies}

In the last decades, the city of Milan has faced several economic, demographic, and political problems [25].

Demography shows a sharp decline in the number of inhabitants from 1973 to 2013, followed by a new increase in recent years. In 1973 , the population reached its highest level $(1,743,427)$ and in the 40 years that followed, the population dropped to 1,240,173 in 2011.

The reasons of this decline were the increased price of housing and the consequent migration of inhabitants towards the big metropolitan area, to buy space at the cost of selling time, due to the poor transportation network and the frustrating traffic in the main access roads to the city.

Another demographic challenge was aging. The average age of the residents in the city is over 45 years, and the decreased birth rates have been compensated by migration (today $20 \%$ of the 
population is represented by an immigrant). Moreover, the families have become very vulnerable and almost one-half of the families are single-parent families.

Milan is an Italian city, and the statistics on Italy show a low growth of GDP, an aging population, a new emigration of talented individuals and students to European cities more oriented to young people, a decreased attitude towards long-term planning, and very little interest in public and private investments in the future.

Despite the previous indicators, in the last years, the city has started to find its specific path, moving against the current and trying to reactivate the economic and entrepreneurial vocation of the city to counter the idea of unavoidable decline.

The pride of the city was been further reinforced in 2015 with the organization of the Expo and the outstanding success of the initiative. The city has become more attractive to tourist, students, and businessmen, and the Expo is still generating movement, tourism, and interest.

It is difficult to attribute the success of this rebirth to one particular event. Milan has a remarkable number of volunteers, a local sense of belonging to the territory, a significant number of universities, and a strong historical and economic tradition.

Under such conditions, in 2017, the President of the Municipal Council of Milan approved the idea to start an unusual think-tank, capable of exploring new choices, to gather new indications and directions about the desirable future of the city and, in for the meantime, to reopen a debate between the city's stakeholders on the role of politics in shaping the future.

\subsection{Logics and Purposes}

The project of Milano 2046 was based on the original concept of projecting a theoretical-practical think-tank about the future considering five fundamental requirements:

1. It had to center on the person using a holistic and integrated approach. The purpose was to establish that the objective of the policy is the citizen.

2. It had to adopt a national or international standard of well-being to avoid partial or debatable views of the "urban interests and priority."

3. It had to develop and improve a perspective of a "far" future beyond studying only a 5- or 10-year urban planning. The aim is to influence actual decision-making and also to try to adopt effective immediate decisions compatible with future goals.

4. It had to design a city useful and attractive to all the citizens, including children, youth, people with disabilities, older people, indigenous people, refugees, internally displaced people, and migrants, as specified in the 2030 Agenda, "leaving no one behind."

5. Lastly, it had to pursue a complete set of knowledge, considering not only the objectives but also the threats with an optimistic (but not shallow) view, bearing in mind that we are not anymore afflicted by hunger, war, or epidemics [35,36].

To achieve these objectives, it was decided to realize a project focused on a practical approach (what to do), skills and methods (how to do) but also (primarily) on philosophical frame and principles of a sustainable city. Therefore, the research started from the motivations and theoretical interpretations of the role of the public administration in forcing, driving, or being disengaged (laissez-faire) from the behaviors of the citizens.

In summary, the goal of the study was two-fold: On the one hand, the project aimed to increase the awareness of the necessity to reinstall the sense of future in the political and collective debate. On the other hand, Milano 2046 was promoted to understand the key issues needed to draw an urban future and to gather new ideas, cognitive instruments, and reflections about the future that would be useful to draw new programs and projects.

The first goals were defined in the "why, how, and what" fields. 


\subsection{Well-being: An Integrated Perspective}

The choice of an adequate set of well-being principles started with a historical perspective of well-being definitions and interpretations. The first agreement was to go beyond the GDP = well-being equation and to consider either the Easterlin's paradox about the relationship between richness and well-being or the significant steps introduced by Robert F. Kennedy in his famous speech (University of Kansas, 18 March 1968) on the cultural poverty of a society concentrated only on GDP: "Too much and for too long, we seemed to have surrendered personal excellence and community values in the mere accumulation of material things ( . . . ) Gross National Product counts air pollution and cigarette advertising, and ambulances to clear our highways of carnage. It counts special locks for our doors and the jails for the people who break them. It counts the destruction of the redwood and the loss of our natural wonder in chaotic sprawl. ( . . . ) Yet the gross national product does not allow for the health of our children, the quality of their education or the joy of their play. It does not include the beauty of our poetry or the strength of our marriages, the intelligence of our public debate or the integrity of our public officials. It measures neither our wit nor our courage, neither our wisdom nor our learning, neither our compassion nor our devotion to our country, it measures everything in short, except that which makes life worthwhile."

This relevant starting point led to a different and wider concept of well-being and many years later, to the Stiglitz Sen Fitoussi Report [37], a milestone in the "person-based" perspective in well-being.

The commission Stiglitz Sen Fitoussi stimulated by former President of France, Nicholas Sarkozy, suggested measuring the well-being of final users (household and citizen) rather than of macroeconomic indicators. Since that step, an increased number of studies have explored well-being, and Milano 2046 considered many of them due to its adoption of a scientific approach in the search of well-being and happiness.

Therefore, the committee highlighted the main procedures, domestic and international. On the international side, the interest has focused on OECD well-being regional index and on the most widespread international set of domains and indicators, represented by the 17 SDGs (United Nations), in committing to the 2030 Agenda for Sustainable Development. OECD well-being index focuses on 11 domains: Housing, income, jobs, community, education, environment, civic engagement, health, life satisfaction, safety, and work-life balance. The domains are based on regional interviews and on the perception of the citizens about the well-being in their regions.

This is the largest and most attractive set of goals but there was, at the same time, the will to consider domestic domains and indicators and to be at odds with the Italian well-being benchmark, as represented by BES [Benessere Equo e Sostenibile (equitable and sustainable well-being)] settled by the Italian Institute of Statistic (Istat) and CNEL (national council of economy and labour).

BES is a multidimensional measurement approach to complement the measures of the key dimensions of well-being, together with measures of inequality and sustainability, related to production and economic activity. (https://www.istat.it/en/well-being-and-sustainability/the-measurement-ofwell-being).

The 129 BES indicators measure 12 domains: Health; education and training; work and life balance; economic well-being; social relations; politics and institutions; security; subjective well-being; landscape and cultural heritage; environment; innovation, research, and creativity; and quality of services.

The choice between the international and domestic domains and indicators has been the object of several debates. The international goals (SDGs) will be, in fact, the future reference of the academic and political debates on progress and global and local goals. Nevertheless, many of the SDGs specific indicators are not relevant (or only partially) for Milan due to the specific situation of the territory. For instance, the goals of the availability of water, use of marine resources, and inclusive quality education have been consistently reached in Milan.

The final decision was to adopt BES as a frame, to be 'closer' to the needs and perceptions of the Milanese citizens and more coherent with the quality of life in an urban context. 
This does not mean that BES is exhaustive or totally consistent with the aim of the laboratory. BES indicators, for instance, focus largely on gender but ignore important variables, like ages, Neets (Italy has a very bad ranking for the percentage of NEETS, young people Not in Education, Employment or Training), and migrants.

Moreover, BES probably underestimates some aspects of subjective well-being, which have been emphasized by sociological studies on human capabilities [38]

On the other hand, as previously anticipated, the adoption of the BES-framework gives Milan the possibility to be closer to the Italian situation and provides statistical data to understand the local situation and to compare it with the situation in similar territories.

\subsection{The Future and Its Challenges}

The second relevant area of "strategic decisions" has involved the future, which started by choosing an adequate timeline and time frame.

When to set the goals of an urban project and why? Here, the general sensation was to define an idealistic but not utopian date connected with history but also with creativity.

The initial idea was to set an iconic deadline capable of identifying the future as a cultural fact and of representing the capacity to aspire [39].

In this respect, Milano 2046 wanted to point out that the task of a laboratory promoted by an "institution" is to draw rather than to plan a vision and to submit this to policy-makers as a new lens to consider as well as to think about the future.

The year 2046 was chosen for two main reasons:

a. On 2 June 1946, a few months after the end of World War Two, the Italian Republic was born, and Italy started rebuilding its society economically, politically, morally, and socially. To imagine the city 100 years after this milestone could be evocative;

b. 2046 is a movie (Wong-Kar-Wai) about a journalist writing a novel about the future where it will be possible to find lost memories.

In the following sessions, we'll present two relevant and actually unfolding processes of the project: The first relates to a specific method considered suitable for gathering objectives about the future of the city, while the second refers to the involvement of institutional subjects in specific settings for sharing and co-projecting sustainable initiatives for the future.

\section{Methodological Approach}

The discussion about methods started by talking about the multidimensional tasks of a city's "well-being". The arguments listed the need to comprehend the definition of well-being (and a recognition of models and best practices); the definition of an efficient organizational structure (and the possibility to be measured); the process of decision-making; the relation to politics and finance; and the adoption of virtuous behaviors by the citizens: Centralism, laissez-faire, libertarian paternalism [36] behavioral finance; and education. Among these aspects, one of the most relevant difficulties was connected to the measures, since to be measured means to be transparent.

This short recognition highlights that Milano 2046 is not just a theoretical think-tank but primarily an attempt to learn new ways to design and shape the future. At the same time, it is not a "marketing operation" or a pre-election activity.

The sincere attempt to imagine the urban future requires a large panel of contributors, dealing with the question about which components of the collectivity have to be involved in a free and democratic search for the future.

The first decision concerned the selection of a committee and choosing experts with knowledge, competencies, and passion about the future. The first selection included a narrow panel of experts with experience in philosophy, demography, social science, welfare, economy and sustainability, quality 
process, research and scenario analysis, writing and communication, management of public processes, and procedures.

The committee's participants were contacted and asked to participate voluntarily and to contribute to the setting of goals, methods, activities, and a timetable.

The second decision pertained to identifying the relevant stakeholders. The need was to have a wide representation of rights and interests; therefore, Milano 2046 contacted the Associations of the Enterprises, the Trade Unions, the Third Sector (Volunteer's Organizations). Another panel comprised the former Mayors who discussed problems they have faced and the ways in which the past defined the present (the present is the future of the past ... ).

The first was achieved in June 2017, and it consisted of the creation of a "logo" and the definition of the claim: "Milano 2046 — a laboratory for a common future" (in Italian, common has a double meaning, because it also identifies a Municipality).

The lab also started an initial recognition of international best practices based on the "long-term" planning, paying attention to Berlin, Stockholm, Paris, Helsinki, Dubai Future Academy, and the fascinating initiative of "Foresight Projects" introduced by the Office for Science of the UK Government. At the same time, any initiative or research had to be conducted in cooperation with the city (and not in the city), had to be open to debate and disagreement, and pushed by the pursuit of the utility of the final users: The citizens.

The Mayor opened the inauguration of the first Committee's meeting to establish the commitment of the local government to the new challenges and strengthen the positioning and significance of a city in the new geopolitical networks.

In this first meeting, the committee made a decision to pay particular attention to cultural aspects and to concentrate the efforts of the urban projects on technology, governance, and mindset.

In July, the first strategic activity was launched: The Policy Delphi (as described in the following section). The aim was to assess the relationship between two dimensions of the cohabitation and progress, specifically well-being and future.

\subsection{Policy Delphi for "Milano 2046"}

The Policy Delphi research for Milano 2046 was developed within the Milano 2046 laboratory. The research was launched in October 2018, and it will end in January 2019. The subsequent months will be devoted to the analysis, synthesis, and dissemination of the results.

The objective of the research is to think, in an innovative and long-term way, about the 12 domains of well-being contained in the Italian Project BES and use them to build a future of well-being in Milan. Many European cities deal with a long-term approach to the future and implementing the BES indicators when utilizing this approach drives innovation.

The research uses the Delphi methodology widely used in social research to gather opinions about an issue/topic using standardized questionnaires.

The Delphi methodology [40-47] is an organized method for correlating views and information pertaining to a specific topic, for allowing the panelist to express their personal views, and for assessing diverse viewpoints.

Three different types of Delphi include the classical or traditional, decision-making and policy [48], with policy Delphi being the most appropriate for the purpose of this research.

Delphi, since its introduction, has dealt with technical topics and sought consensus among homogeneous groups of experts. The Policy Delphi, on the other hand, seeks to generate the strongest possible opposing views about a major policy issue [49]. Therefore, the methodology is not intended to replace public administration activities but to precede them. Thus, it helps the decision/policy maker make a well-informed decision on the matter, which is exactly the approach we need for our research.

The purpose of our (Policy) Delphi research is to gather information, long-term visions, and opinions of those who contribute to the long-term development of Milan. 
Imagining the future means reflecting on the desired situation, in this case, a situation in a remote future and translating it into practical goals. Building the future also means considering potential future shocks, risks, and threats that can make the expected future impracticable.

For this reason, we found it useful to combine research on future objectives for Milan with research on future shocks for each one of the 12 domains of well-being contained in the BES Project.

The first aim of the research is to obtain a local assessment of the priorities for the future of Milan identified by the main protocols in place (BES-Italy, SDGs-United Nations) and of the entity of threats (future shocks) that could hinder the objectives using the WEF Global Risk Report. The second aim is to collect the data on the respondents' new visions and new desirable objectives as well as new risk factors facing the city of Milan. In both cases, the respondents will be asked to express consent or disagreement with the average opinions of the sample. This procedure is applied to all twelve domains of the BES; therefore, the study comprises 12 parallel sub-inquiries: Health, education and training, work, economic wellbeing, social relations, politics and institutions, security, subjective wellbeing, landscape, and cultural heritage, environment, innovation research and creativity, quality of services.

The questionnaires are distributed via an online survey tool. One of the great advantages of the Delphi method, as a tool in policy analysis, is its minimal cost for maximum output. The great amount of data which may be derived and the opportunity to facilitate a discussion among individuals (experts, stakeholders, and community) in the dimension makes this method cost-effective.

\section{The Stages of Delphi Research}

The research provides some distinct phases:

- $\quad$ Phase 0: Invitation and engagement of panel of experts

- Phase 1: Exploration of the topic/domain. Each respondent provides additional information that he/she feels is pertinent to the issue.

- $\quad$ Round 1: Reaching an understanding of how the group's perception of the issues (desirability of objectives and riskiness of future shocks for Milan)

- $\quad$ Round 2: Reaching consensus on the desirability of objectives and riskiness of future shocks

The "zero" phase is a propaedeutic step, as during this first important moment, panelists have been invited to take part in the research.

A list of more than four hundred highly selected potential respondents were created from among the most notable local experts in the field and from those who influence the dimension. Invitations to participate in the study were sent to 402 individuals within 12 sub-groups selected based on their experience and competence in the above-mentioned domains. In this step, we described the meaning of their participation, the guarantee of the anonymity of the participants, the expected workload, and the conditions of transparency and awareness.

To gather heterogeneous and complementary perspectives, individuals with diverse visions, experiences, interests, and different views were identified. For this reason, each sub-research involves:

- Experts (University lecturers, professionals in the field, researchers/scholars/writers/specialized journalists)

- Stakeholders (representatives of a private organization involved in the domain)

- Community (individuals from the community not belonging to the previous categories, with a focus on young people in suburbs)

The first phase of the Delphi research began by sending out questionnaire 1, which contained open qualitative questions aimed at identifying different objectives and future shocks envisioned for Milan. In this phase, the theme was framed and a general picture of the research question was drawn in order to outline a future direction and identify a new list of desired future objectives and future shocks for Milan, which will form the basis of the subsequent phases. 
To prevent the respondents from starting from a blank sheet, as mentioned above, we decided to present some of the future objectives included in the BES/SDGs domains (United Nations Sustainable Development Goals) and future shocks included in the 2017 Global Risks Report of the World Economic Forum / Cambridge Global Risk Outlook 2017.

The first questionnaire ended with an open question about the future of Milan in relation to the dimension investigated.

Questionnaire 1
Objectives
Which objectives should be at the center of long-term local policies of Milan?
Paying attention to the inequalities (gender, class, age, origin, and the
center-periphery dynamics, etc.), we invite you to indicate up to 3 objectives,
different from those suggested above, which you deem worthy of attention for the
future of Milan.
From your point of view, what are the main future shocks that, in the coming years,
could hinder the achievement of the indicated objectives?
Based on your knowledge, experience, and opinions, please indicate 3 future risks
that you consider worthy of attention and necessary to consider.
How do you imagine "health/work/environment... " in Milan in 2046?

The first analysis of the answers was conducted and consisted in the identification of similar questions, that could be aggregated, and in the creation of an exhaustive but at the same time a limited list of objectives and future shocks. The analysis of the answers of questionnaire 1 carried out by the research team led to the construction of questionnaire 2 .

During the second round, the participants had to complete two separate assignments.

The first assignment required the participants to classify the objectives contained in the BES/SDGS, focusing on the priorities for Milan, and to classify the future shocks included in the WEF Global Report Risk, focusing on the threats for the future of Milan.

Finally, the list of new objectives and future shocks suggested during the previous phase is proposed to the sample. The respondents had to assess the desirability of each new objective and assess the riskiness of each future shock on a 5-point Likert-scale (from 1 to 5) and explain the motivations for their choice if desired. The analysis of the answers of the questionnaire 2 is now ongoing, and the opinions expressed by the participants have been describing through statistical summaries (average, mode, interquartile range, standard deviation). We will examine the central tendencies towards which the answers of the panel are oriented along with their distance from the average and the interval.

Objectives (BES/SDGS)

Future Shocks (BES/SDGS)

List of new future objectives

List of the new future shocks

\section{Questionnaire 2}

Please classify the objectives included in BES and SDGS and proposed in the Q1 previous phase, considering the effective possibility of being implemented by the public administration of Milan.

Please classify the future shocks included in the Global Risk Report and

Q2 proposed in the previous phase, considering the effective riskiness for the future of Milan.

Please assign a score from 1 (minimum) to 5 (maximum) on the "desirability" Q3 of each new objective. We remind you that your assessment must refer to the city of Milan.

We ask you to assign a score from 1 (minimum) to 5 (maximum) on the

Q4 "riskiness" of each new risk. We remind you that your assessment must refer to the city of Milan. 
The outcome of Round 1 is a new questionnaire (number 3) that has been submitted to the same sample during Round 2 for a consensus evaluation.

Questionnaire 2 requires a new assessment of the desirability of objectives and riskiness of future shocks. In this round, the interquartile range for each item is highlighted. The interquartile range is the difference between the first quartile (25th percentile) and the third quartile (75th percentile) of an ordered range of data. It contains the middle 50 percent of the distribution (panelists' evaluations) and is unaffected by extreme values. We use the interquartile range because it is a valid approach to stimulate a convergence between respondents' evaluations.

Considering the interquartile range, during the last round, we asked the panelists to think again about the desirability of the objectives and the riskiness of the future shocks and to assign a new score to each item.

This round gives the respondents an opportunity to re-evaluate their scores after reviewing their initial scores and comments from their fellow participants. Everyone will be able to reflect on how the other participants evaluate the topic. All those who deem it appropriate to assign a score outside the highlighted interquartile range will, therefore, be invited to explain their motivation anonymously in a written form.

Questionnaire 3
For each objective identified in the first phase, the interval containing half of the
evaluations expressed by the research participants (sample) is highlighted. Based on
this information, and always keeping the future of the city of Milan in focus, we ask
you again to indicate a score on the desirability of the objective that goes from 1
(minimum) to 5 (maximum). If you do not agree with the assessments highlighted,
we ask you to express your thoughts.
For each future shock identified in the first phase, the interval containing half of the
evaluations expressed in the previous round by the participants in the research is
highlighted. Based on this information, and always keeping the future of the city of
Milan in focus, we ask you to express again on the "riskiness" that goes from 1
(minimum) to 5 (maximum). If you do not agree with the average panel evaluations,
we ask you to express your thoughts.

The research ends with the list of objectives (BES, SDGs) and risks (Global Risk Report) classified according to the priority for the city of Milan and with a list of new objectives (classified following a desirability scale) and new future shocks (classified following a scale of risk) for each BES domain. In addition, further reflections will be provided based on descriptive and frequency statistics (for example, mean, mode, median, and standard deviation, among others, as mentioned previously).

The results of the research will be made available to citizens to fuel the debate and to provide the public policy with further interpretation and reflection. This "feedback" makes the research close to the end users who could also express their opinions in terms of priority and importance. The "decision makers" will, therefore, have a statistical representation of the thoughts and outcomes by the end users.

In summary, at the end of the research, we expect to deliver to the Municipal Council:

- A set of objectives (from BES/SDGs) and future shocks (from Global Risk Report) in order of the priority and riskiness for the future of Milan

- A set of new desirable objectives for the design of the future city / cities. These objectives could serve as an agenda that could be shared with and submitted to other cities

- A prioritized list of future shocks that could threaten objectives

- A new way of describing and interpreting sustainability (dimensions of well-being) realized with experts, stakeholders, that can help to develop future initiatives and policies

- A final report with all the results will be the basis for further research

- Acquisition of cultural and planning leadership in terms of urban sustainability 
- "Re-installation" of the future within the overall planning of public administration policy

- Knowledge and skills that are useful for the creation of a permanent laboratory on the future based on models of the professional design of citizens' well-being powered by consistent data and networks of relationships.

\subsection{Involving Collective Subjects in the Generation of Ideas}

The second aim of the Milano 2046 is to involve different collective and institutional subjects in order to identify a wide representation of rights and interests connected to the future of the city. To achieve this aim, different meetings were organized to involve the various stakeholders, specifically, the former mayors of the city, representatives of the third sector, delegates of the main universities in the city, and representatives of the unions.

The objectives of the meetings were to (1) present the intents and scope of the Lab Milano 2046, (2) investigate the most important issues related to sustainability and the future of the city from the perception of the subjects involved, and (3) investigate the possibility to develop projects that can respond to the needs and objectives of both parties.

All meetings were organized in the same setting and with the same structure. Three main steps included the presentation of the history, motives for and aims of Milano 2046 in the first phase; in the second phase, an open discussion in which the participants were asked to express and explain their ideas about the significance and prospects of Milano 2046; in the third phase, summary of the key aspects necessary to develop co-constructed projects that can create shared value.

The meetings were audio recorded and transcribed. The analysis of the transcriptions allowed us to identify contents and themes related to the sustainable future of the city that were considered significant from the perspective of the participants. Furthermore, the discourses highlight the resources that the participants identified as necessary for developing shared projects and initiatives.

The Table below provides a summary of contents and resources (Table 1).

It is important to mention some challenges that emerged from the discussions with different participants. The first one is connected to the strong expectations of the participants to receive precise directions and proposals of collaboration. At the conclusion of the first phase of the meeting (presentation of the history, motives, and objectives of Milano 2046), the participants wanted to know what actions and tasks we had identified and expected them to complete. In this sense, we found some disorientation and resistance towards a form of dialogue that we interpreted based on the co-construction and identification of shared needs and interests. The second one is related to the difficulty in integrating the various positions transversally. In some way, it was easier to find a connection between the Milano 2046 and each interlocutor while it was particularly challenging to find a transversal way to promote collaboration among all the parties involved. For this reason, we decided to organize other meetings individually with each participant to share with them the significant issues that emerged during the first meeting and to connect these with their individual interests. In the following paragraph, we describe the projects that emerged from the following dialogue with the representatives of each University.

Table 1. Stakeholder generative map.

\begin{tabular}{|c|c|c|c|}
\hline $\begin{array}{l}\text { Subjects } \\
\text { Involved }\end{array}$ & Key Elements & Resources & Quotes \\
\hline Unions & $\begin{array}{l}\text { 1. Transformations and } \\
\text { future of work (new } \\
\text { professions, opportunities, } \\
\text { and risks of unemployment } \\
\text { and underemployment) } \\
\text { 2. Inequalities in the } \\
\text { education system }\end{array}$ & $\begin{array}{c}\text { Already activated } \\
\text { projects in the territory } \\
\text { Networks }\end{array}$ & $\begin{array}{l}\text { "the idea to open the project to } \\
\text { different stakeholders is } \\
\text { important also because the } \\
\text { various subjects involved can } \\
\text { help to make the ideas into action } \\
\text { by connecting the strategies } \\
\text { identified for Milano } 2046 \text { with } \\
\text { already existent projects of for } \\
\text { example organizations that our } \\
\text { inside our networks" }\end{array}$ \\
\hline
\end{tabular}


Table 1. Cont.

\begin{tabular}{|c|c|c|c|}
\hline $\begin{array}{l}\text { Subjects } \\
\text { Involved }\end{array}$ & Key Elements & Resources & Quotes \\
\hline $\begin{array}{l}\text { Previous } \\
\text { Mayors }\end{array}$ & $\begin{array}{l}\text { Strategies for the PA in the } \\
\text { implementation of policies } \\
\text { oriented to the future. } \\
\text { In particular: } \\
\text { 1. Promote collaboration and } \\
\text { sharing of the best practices } \\
\text { between different areas of } \\
\text { the city for the } \\
\text { implementation of actions } \\
\text { and projects based on } \\
\text { sustainability. } \\
\text { 2. Listen to the citizens' } \\
\text { needs and the } \\
\text { co-construction of policies } \\
\text { with them (e.g., participatory } \\
\text { budgeting). } \\
\text { 3. Interpreting the role of } \\
\text { politics as based on the } \\
\text { collaboration and } \\
\text { competition between } \\
\text { different political parties. }\end{array}$ & Previous policies & $\begin{array}{c}\text { "Listening of people must be } \\
\text { accompanied by a challenge } \\
\text { between the zones: During the } \\
\text { mandate, a premium program } \\
\text { was activated for the areas with } \\
\text { the highest share of separate } \\
\text { collection" }\end{array}$ \\
\hline Universities & $\begin{array}{l}\text { 1. Innovation and the effect } \\
\text { of technologies. } \\
\text { 2. Distribution of well-being } \\
\text { and inequality between } \\
\text { different groups of people } \\
\text { and areas of the city. } \\
\text { 3. Environment } \\
\text { (improvement of green } \\
\text { areas). } \\
\text { 4. Immigration (analysis of } \\
\text { the characteristics of the } \\
\text { current phenomenon of } \\
\text { immigration and the } \\
\text { possible consequences). }\end{array}$ & $\begin{array}{l}\text { Young students } \\
\text { Multi-disciplinarity }\end{array}$ & $\begin{array}{l}\text { "We work with and for the } \\
\text { protagonist of the future, the } \\
\text { young generation. It is important } \\
\text { to work with them if we want to } \\
\text { think about the future of the city"; } \\
\text { "we can create added value from } \\
\text { the integration of the different } \\
\text { perspectives. For example, in our } \\
\text { university, a multidisciplinary } \\
\text { research group is working on the } \\
\text { future of our university." }\end{array}$ \\
\hline $\begin{array}{c}\text { Voluntary } \\
\text { /Tertiary sector }\end{array}$ & $\begin{array}{l}\text { 1. Inequality between } \\
\text { groups of people and areas. } \\
2 \text {. Difficulty to access } \\
\text { services in the territory for } \\
\text { all the people categories } \\
\text { 3. Citizens social support as } \\
\text { a way to respond to their } \\
\text { own needs (e.g., social } \\
\text { streets). }\end{array}$ & $\begin{array}{l}\text { Already activated } \\
\text { projects in the territory } \\
\text { Relationship with and } \\
\text { between groups of } \\
\text { citizens }\end{array}$ & $\begin{array}{c}\text { "Milan is one of the cities with } \\
\text { most social streets in the world, } \\
\text { but it is important to find ways to } \\
\text { look beyond the neighborhood. } \\
\text { What is needed is to take a look at } \\
\text { the entire city to construct a } \\
\text { social city." }\end{array}$ \\
\hline
\end{tabular}

A Focus on the Involvement of the Universities: Towards Collaborative Projects

The first meetings identified possible initiatives that could be developed to promote a sustainable city. Through several meetings conducted separately with each university, we identified two different projects that could be developed together.

The first project related to the "production of knowledge" is called "young researchers." The project involves the creation of a transdisciplinary research group of students from different universities who are doing their master thesis or $\mathrm{PhD}$ thesis.

The research group is dedicated to the deeper understanding of issues connected to the theme of sustainability and the future of the cities and related to the 12 dimensions of the BES presented previously. The aim is to understand the complexity of the topic of sustainability and the future of cities using different approaches. Each university is asked to select 2 or 3 students who are interested in approaching the topic from a specific perspective (e.g., health and new technologies, unemployment and industry 4.0, educational segregation, and the like).

In this sense, the research group comprises two to three students from each university who contribute to the research project with specific perspectives. 
The group is coordinated by representatives of Milano 2046 and selected tutors from the universities (professors or senior researchers) who are asked to organize periodic meetings with the young researchers to connect them with different perspectives and to integrate the theoretical aspect with the practical one (the implementation of public policies by the PA). In addition, the intention is to present the results of the research group to the public through a public event open to the citizens and collect the feedbacks and comments on the issues addressed.

The second project aims to "share knowledge" about the issues of sustainability and the future of cities. In this regard, the initiative is to implement a summer school co-constructed by Milano 2046 and the universities. The summer school is intended for multiple subjects: Public administrators, university professors, $\mathrm{PhD}$ candidates, and members of organizations and associations that deal with local policies.

The various aims of the schools are connected to three main areas:

1. "Knowing what" (information): Share the basic knowledge necessary to understand the concepts related to sustainable development in a systemic and integrated way;

2. "Knowing how to do" (competencies and skills): Develop the skills necessary to understand, tackle, and plan the future (research, mapping of the present, predicting and planning, simulation methods, scenario evaluation, tests, etc.);

3. "Knowing how to be" (attitudes, values): Reflect on the philosophical, psychological, anthropological, and ethical themes that stimulate the attitude towards the common good and sustainability as lenses through which we should look at the world and reflect upon issues pertaining to freedom, justice, and equity.

To support the co-construction of the project, the summer school is coordinated by a scientific committee consisting of representatives of Milano 2046 and representatives of the Universities. The committee is responsible for elaborating on and approving the program (syllabus) and methodology of the school; identifying the teachers for lectures; supporting the school through communication activities in its area of reference; and validating the criteria for selecting candidates.

The two initiatives described are in the phase of planning, and the LabMilano2046 will launch the two projects in the upcoming months in 2019 with an aim to deeper understanding and developing the results collected with the Delphi survey.

\section{Discussion}

The complex process of involvement of different subjects previously described has been successful with a number of participants and interests.

Sixty-three percent of an identified sample of 395 citizens, 249 people-166 male (66\%), 83 female (33\%) agreed to participate in a Delphi research and took part in the first phase of the research (questionnaire 1). Of the citizens involved with the first step $222(89 \%)$ participated in the compilation of the second questionnaire (see Table 2). 
Table 2. Participation rate.

\begin{tabular}{lll}
\hline BES & Citizens Involved (Questionnaire 1) & Citizens Involved (Questionnaire 2) \\
\hline 01-Health & 25 & 20 \\
02-Education and Training & 18 & 16 \\
03-Work & 19 & 16 \\
04-Economic Wellbeing & 29 & 24 \\
05-Social relations & 30 & 27 \\
06-Politics and Institutions & 13 & 12 \\
07-Security & 15 & 14 \\
08-Subjective wellbeing & 27 & 24 \\
09-Landscape and Cultural heritage & 21 & 19 \\
10-Environment & 17 & 17 \\
11-Innovation, Research and & 14 & 13 \\
Creativity & 21 & 19 \\
12-Quality of services & 249 & 221 \\
Total & & \\
\hline
\end{tabular}

In the first questionnaire, people were asked to indicate up to three objectives and risks, and almost all the subjects decided to provide the maximum of the answers they had at their disposal.

Thus it was possible to collect a large amount of qualitative data for the research team to analyse and synthesize. The analysis identified of a total of 343 future objectives and 329 risks, divided as presented in Table 3.

Table 3. Number of objectives and risks identified.

\begin{tabular}{lll}
\hline BES & Objectives & Risks \\
\hline 01-Health & 31 & 30 \\
02-Education and Training & 25 & 32 \\
03-Work & 25 & 31 \\
04-Economic Wellbeing & 31 & 29 \\
05-Social relations & 34 & 30 \\
06-Politics and Institutions & 8 & 12 \\
07-Security & 29 & 25 \\
08-Subjective wellbeing & 33 & 40 \\
09-Landscape and Cultural heritage & 34 & 28 \\
10-Environment & 25 & 19 \\
11-Innovation, Research and Creativity & 31 & 25 \\
12-Quality of services & 37 & 28 \\
Total & 343 & 329 \\
\hline
\end{tabular}

In the same line, we registered a high level of participation for the collective concerns of the subjects. In particular, we realized a table of discussion with representatives of 13 organizations in the third sector (of 19 invited), seven previous majors (of 9 invited), representatives of five trade unions (of 5 invited) and representatives of all the main universities in the city ( 8 of 8 invited). In addition, all the universities decided to take part actively in the scientific committee of the projects previously described.

\subsection{Implications for Citizens, Policy-Makers, and Societies}

The process activated has been successful in its aims to involve citizens and collective subjects in the processes of knowledge sharing through a dialogical approach that can help to identify problems and develop strategies for dealing with complexities.

This approach has produced implications at various levels.

First of all, the citizens who were involved in the study, as they expressed by email, feel engaged, involved, and authors in the process of decision making. This, of course, maximized the amount of information and knowledge collected, thus constituting a stronger basis for the policies that will be implemented.

On the other hand, the involvement of numerous citizens and subjects increases the responsibility of policy makers, as they are expected to address issues of common interest for the construction of 
the future of the city and to include the various perspectives presented and underlined by the people involved. The higher the quality of the process activated, the more relevant and challenging the responsibility to realize and translate into practice the suggestions received.

Another important implication of the adopted approach is the importance of accomplishing a collaborative and transdisciplinary perspective in the identification of the issues to be addressed and in the development and implementation of projects and actions. This implication clearly emerged in particular with the involvement of the collective subjects. The challenge in this case, is that of developing solutions to the issues identified, not only by putting together in a mechanistic way the diversity of knowledge provided by the subjects but also by generating new knowledge different from what could have been produced by any one subject working alone.

The Milano 2046 project is actually unfolding. Some considerations and comments can be provided in relation to the methodology adopted in the project and to answer the research questions addressed in the paper.

Referring to the first question related to the development of processes of sharing and knowing, we can highlight the huge connection between the approach of the project and the literature on multi-stakeholdership, sustainability, and social participation. Specifically, some scholars $[10,50]$ claimed for sharing as brokering meanings among the experts, that means the possibility to arrange or mediate an agreement between different institutional and organizational subjects. Three brokering practices are described: Connecting, grafting, and dealing. The first concerns creating the condition for a reciprocal communication among different experts; the second relies on detecting different interpretations and interests and on the need to insert them (uploading) in a common infrastructure to be commonly discussed and clarified; and the third is about creating possible new way to cope with specific problems, perceived as common and related to the joint filed of interest.

The above-described Delphi methodology is in line with the multi-stakeholder's approach, as it follows the structured phases and steps to achieve common meanings and shared fine-tuning convergent issues. It can also prevent and possibly avoid two risks that are always at stake in pluralistic contexts characterized by diffuse power, divergent objectives, and knowledge-based work processes: The dilution of initiative and the inflationary consensus [51]. The former is concerned with the multiple organizational and institutional layers that have to be crossed, negotiated, and managed to achieve common and convergent interpretations. Due to the articulated structure of the knowledge-gathering process, the Delphi approach reduces the length of time necessary to cross the multiple levels of the meaning's negotiation, overcoming the physiological inertia related to the matching of different and often polarized representations. The latter refers to the need to ensure the involvement of all the committed actors due to the different influence of multiple stakeholders on determining orientations and meanings. Additionally, in this case, the Delphi phases allow a structural involvement of all participating stakeholders.

Moreover, institutional dialogue with different collective subjects provides relevant opportunities for situated and collective actions, generating a progressive accomplishment of acts of knowing [11]. This facilitates the creation of forms of collective learning in situ $[9,12]$ and allows for the identification of local contingencies and contextualized criticalities and situations. The meetings and stakeholder map can enhance social processes of knowledge creation and sense-making [52], while considering different cultures, knowledge systems, mental models, and languages. Thinking about the project of the summer school and its main contents, we can also acknowledge the different components of an integrated view of sustainability: Personal (competencies and skills), social (shared attitudes and values) and organizational (related to knowledge circulation and improving integration among different collective subjects).

In relation to the second research question concerning suitable conditions for a stakeholder engagement in a sustainable urban future, we can underline the ability of the process owners of the project to provide and shape an inter-organizational partnership as an important system of engagement. The complex and pluralistic context utilized in Milano 2046 project can be associated with scenario 
planning, which is 'a structured analytical activity to create multiple futures to help stakeholders re-perceive reality and thus improve strategic and/or policy decisions' [53]. Instead of an analytical and well-defined concept, the label refers to an 'intuitive logic' that conveys processes of sensemaking, organizing, and storytelling. Discursive and conversational practices, selection of key drivers (as the goals and issues described in the above paragraphs), group discussions, exchanges between stakeholders and organizational actors are all relevant elements of the flux of sensemaking stories generated by ensuring polyphony and pluri-vocality $[54,55]$

Another condition concerns the awareness of the ideological and political function that the process conveys, seeking to define suitable, sustainable, positive, and attainable future. As a product of human action, the Milano 2046 project relies on both explicit (as in the Delphi issues and process) and implicit conditions embedded tacit knowledge and unwritten rules and plural sets of working procedures related to different collective subjects (see the difficulties in matching transversal positions). A strong agreement among the multiple partners and stakeholders involved must be achieved to ensure the suitable and sustainable development of the social activity set up that entails also the assumption of the ambiguity entangled in the process of polyphonic and relational knowing.

Social dimensions embedded in pluralistic contexts suggest the third condition, that is, the management of networking and knot-working practices [56] necessary to cope with different groups, divergent interests-goals-objectives and multiple organizing processes that characterize the multi-stakeholdership involvement. While networking refers to plural and articulated connections and relationships among different people required to deal with emerging demands through the circulation of shared knowledge, knot-working refers to a negotiating agreement and collaborative adjustments to tackle convergent and shifting situations. Both networking and knot-working perspectives are intertwined and entangled in the process of collaboration between multiple partners seeking to enhance a common endeavor. This entails facing internal and external pressures that can generate three main situations [57,58]: A reciprocal interdependency in which the process of multi-stakeholders engagement yields the convergent acknowledgment of common issues and objects; a destructive conflict among polarized and antagonistic positions that impede the possibility to negotiate a common direction; an imbalanced inertia related to incoherent practices; organizational deflections that slow down or block the development of the process.

Actually, Milano 2046 seems to enhance a good enough interdependency, since it utilizes a Policy Delphi research and a summer school, thinking about the next steps. The next monitoring will be conducted in June 2019, and the Municipal Council will decide about the extension of the projects. The laboratory is involved in new projects, from summer school offered in cooperation with the Universities to a Well-being Cinema Festival.

\section{Conclusions}

The paper addresses problems with and the practical implications of enhancing collective endeavors towards sustainability, seeking to understand how multi-stakeholdership and partnership can be sustainably accomplished by different people, groups, and collective subjects.

The case study reveals that to gain prompting and nurturing sharing and knowing opportunities, we have to promote brokering practices, avoiding the risks of dilution of initiative and the inflationary consensus. The Delphi approach provides suitable opportunities to achieve common meanings and convergent issues, while meetings and a stakeholder map can be useful for enhancing institutional dialogue with plural collective subjects from different cultures, knowledge systems, mental models, and languages.

Specific conditions can support the engagement of multiple stakeholders in a sustainable urban future. These conditions include shaping and activating scenario planning suitable for spreading discursive and conversational practices, group discussions, and exchanges between stakeholders to ensure their polyphony and pluri-vocality; managing the ideological and political function and coping with the ambiguity entangled in the social activity set up; and developing 
networking and knot-working practices to generate reciprocal interdependency in the process of multi-stakeholders' engagement.

This study is limited in that it cannot provide empirical evidence to support the final outcomes of the project because of its unfolding development that impedes the use of the final data. Nevertheless, focusing on the methodology approach and the participatory methods applied, the reflexive analysis of the authors involved in the project yields comments about the multi-stakeholdership process at stake. The ability to depict a sustainable future depends on the mobilization of various stakeholders involved in each such relevant endeavor. Higher quality and sustainability of the multi-stakeholder involvement process are associated with more well defined and actionable perspectives for a sustainable future. The use of coherent and diversified approaches (well-structured and defined, as in the case of Delphi methods, or more discursive approaches unfolding flux of sensemaking stories, as in the meetings with stakeholders) help to enhance the embedded sustainability of the process itself.

Its transversal features related to the necessity to explore the dynamics and inter-relationships between different "well-being domains" and between different stakeholders represent open suggestions to be addressed in further studies. A new phase could be proposed to investigate the relationships between well-being domains. The future of a city cannot be designed with an "organ pipes" approach without exploring the relation between health and education or between the environment and the subjective well-being and so on. This requires a second level of research and a new level of participation where specific categories of stakeholders (enterprises, volunteers) influence each other and thus need to consider the perspective of the "other party" to prevent conflict and develop an integrated vision for the project of the city in 2046.

Author Contributions: S.I. (writing and participation in the project Milano2046), F.B. (writing and participation in the project Milano2046), S.S. (writing and participation in the project Milano2046), G.S. (writing).

Funding: We do not have funding for the project.

Conflicts of Interest: The authors declare no conflict of interest.

\section{References}

1. Løwendahl, B.; Revang, Ø. Challenges to existing strategy theory in a post-industrial society. Strateg. Manag. J. 1998, 19, 755-774. [CrossRef]

2. Dyllck, T.; Hockerts, K. Beyond the business case for corporate sustainability. Bus. Strategy Environ. 2002, 11, 130-141. [CrossRef]

3. Guerci, M.; Shani, A.B.; Solari, L. Sustainable Human Resource Management from a stakeholder perspective: Literature review and a research agenda. In Handbook of Sustainability and Human Resource Management; Ehnert, I., Harry, W., Zink, K.J., Eds.; Springer: Berlin/Heidelberg, Germany, 2014; pp. 199-238.

4. Glynn, M.A.; Barr, P.S.; Dacin, M.T. Pluralism and the problem of variety. Acad. Manag. Rev. 2000, 25, 726-734. [CrossRef]

5. Kathlee, M.E. Paradox, spirals, ambivalence: The new language of change and pluralism. Acad. Manag. Rev. 2000, 25, 703-705.

6. Galuppo, L.; Gorli, M.; Scaratti, G.; Kaneklin, C. Building social sustainability: Multi-stakeholder processes and conflict management. Soc. Res. J. 2014, 10, 685-701. [CrossRef]

7. Freeman, R.E. Strategic Management: A Stakeholder Approach; Cambridge University Press: Cambridge, UK, 2010.

8. Freeman, R.E.; Harrison, J.F.; Wicks, A.C.; Parmar, B.L.; de Colle, S. Stakeholder Theory, The State of the Art; Cambridge University Press: Cambridge, UK, 2010.

9. Brown, J.S.; Duguid, P. Organizational learning and communities-of-practice: Toward a unified view of working, learning and innovation. Organ. Sci. 1991, 2, 40-57. [CrossRef]

10. Bechky, B.A. Sharing meaning across occupational communities: The transformation of understanding on a production floor. Organ. Sci. 2003, 14, 312-330. [CrossRef]

11. Orlikowski, W.J. Knowing in practice: Enacting a collective capability in distributed organizing. Organ. Sci. 2002, 13, 249-273. [CrossRef] 
12. Suchman, L. Plans and Situated Actions: The Problem of Human Machine Communication; Cambridge University Press: New York, NY, USA, 1987.

13. Sørensen, E.; Torfing, J. Introduction: Collaborative innovation in the public sector. Public Sect. Innov. J. 2012, 17, 1-14.

14. McCann, P.; Ortega-Argiles, R. Modern regional innovation policy. Camb. J. Reg. Econ. Soc. 2013, 6, $187-216$. [CrossRef]

15. Bason, C. Leading Public Sector Innovation. Co-creating for a Better Society; The Policy Press: Bristol, UK, 2010.

16. Ansell, C. Collaborative governance. In The Oxford Handbook of Governance; Levi-Faur, D., Ed.; Oxford University Press: Oxford, UK, 2012; pp. 498-511.

17. Roloff, S. Learning from multi-stakeholder networks: Issue-focussed stakeholder management. J. Bus. Ethics 2008, 82, 233-250. [CrossRef]

18. Bommert, B. Collaborative innovation in the public sector. Int. Public Manag. Rev. 2010, 11, 15-33.

19. Project Management Institute. A Guide to the Project Management Body of Knowledge, 3rd ed.; Project Management Institute Inc.: Newtown Square, PA, USA, 2004.

20. Di Fabio, A. The psychology of sustainability and sustainable development for well-being in organizations. Emerging and Re-Emerging Organizational Features, Work Transitions and Occupational Risk Factors: The Good, the Bad, the Right. An Interdisciplinary Perspective. Front. Psychol. Sect. Org. Psychol 2017, 8. [CrossRef]

21. Di Fabio, A. Positive Healthy Organizations: Promoting well-being, meaningfulness, and sustainability in organizations. Emerging and re-emerging organizational features, work transitions and occupational risk factors: The good, the bad, the right. An interdisciplinary perspective. Front. Psychol. Sect. Org. Psychol 2017, 8. [CrossRef]

22. Di Fabio, A.; Rosen, M.A. Opening the Black Box of Psychological Processes in the Science of Sustainable Development: A New Frontier. Eur. J. Sustain. Dev. Res. 2018, 2, 1-6. [CrossRef]

23. Laszlo, A.; Laszlo, K.C.; Dunsky, H. Redefining success: Designing systemic sustainable strategies. Syst. Res. Behav. Sci. 2010, 27, 3-21. [CrossRef]

24. Mohrman, S.A.; Worley, S.G. The organizational sustainability journey: Introduction to the special issue. Organ. Dyn. 2010, 4, 289-294. [CrossRef]

25. Lozza, E.; Castiglioni, C. Tax climate in the national press: A new tool in tax behaviour research. J. Soc. Polit. Psychol. 2018, 6, 401-419. [CrossRef]

26. Castiglioni, C.; Lozza, E.; Bosio, A.C. Lay People Representations on the Common Good and Its Financial Provision. SAGE Open 2018, 8, 2158244018807247. [CrossRef]

27. Konrad, A.; Steurer, R.; Langer, M.E.; Martinuzzi, A. Empirical findings on business—Society relations in Europe. J. Bus. Ethics 2006, 63, 89-105. [CrossRef]

28. Hemmati, M. Multi-Stakeholder Processes for Governance and Sustainability: Beyond Deadlock and Conflict; Earthscan Publications: London, UK, 2002.

29. Shani, A.B.; Mohrman, S.A. Organizing for sustainable effectiveness: Reprise and way forward. In Organizing for Sustainability; Mohrman, S.A., Shani, A.B., Eds.; Emerald: Bingley, UK, 2011; pp. 215-237.

30. Smith, W.K.; Lewis, M.W. Toward a theory of paradox: A dynamic equilibrium model of organizing. Acad. Manag. Rev. 2011, 36, 381-403.

31. European Union (2000) Lisbon European Council 23 and 24 March 2000. Presidency Conclusions. Available online: http:/ / www.europarl.europa.eu/summits/lis1_en.htm (accessed on 3 February 2019).

32. Jordana, J.; Mota, F.; Noferini, A. The role of social capital within policy networks: Evidence from EU cohesion policy in Spain. Int. Rev. Admin. Sci. 2012, 78, 642-664. [CrossRef]

33. Furedi, F. Politic of Fears: Beyond Left and Right; Continuum International: London, UK, 2005.

34. Rushkoff, D. Present Shock: When Everything Happens Now; Penguin: New York, NY, USA, 2013.

35. Sørensen, E.; Torfing, J. Enhancing collaborative innovation in the public sector. Admin. Soc. 2011, 43, 842-868. [CrossRef]

36. Harari, Y.N. Homo Deus: A Brief History of Tomorrow; HarperCollins: New York, NY, USA, 2017.

37. Thaler, R.; Sunstein, C. Nudge: Improving Decisions About Health, Wealth and Happiness; Yale University Press: New Haven, CT, USA; London, UK, 2008. 
38. Stiglitz, J.; Sen, A.; Fitoussi, J.P. Report by the Commission on the Measurement of Economic. Performance and Social Progress. Available online: https:/ / ec.europa.eu/eurostat/documents/118025/118123/Fitoussi+ Commission+report (accessed on 14 September 2009).

39. Nussbaum, M. Creating Capabilities. In The Human Development Approach; The Belknap Press of Harvard University Press: Cambridge, MA, USA; London, UK, 2011.

40. Appadurai, A. The Capacity to Aspire. Culture and the Terms of Recognition. In Culture and Public Action; Stanford University Press: Stanford, CA, USA, 2004; pp. 59-84.

41. Adler, M.; Ziglio, E. Gazing into the Oracle: The Delphi Method and Its Application to Social Policy and Public Health; Jessica Kingsley Publishers: London, UK, 1996.

42. Avella, J.R. Delphi Panels: Research Design, Procedures, Advantages, and Challenges. Int. J. Dr. Stud. 2016, 11, 305-321. [CrossRef]

43. Giannarou, L.; Zervaz, E. Using Delphi technique to build consensus in practice. J. Bus. Sci. Appl. Manag. 2014, 9, 65-82.

44. Gordon, T.J.; Pease, A. RT Delphi: An Efficient, "Round-less", Almost Real Time Delphi Method. Technol. Forecast. Soc. Chang. 2006, 73, 321-333. [CrossRef]

45. Habibi, A.; Sarafrazi, A.; Izadyar, S. Delphi Technique Theoretical Framework in Qualitative Research. Int. J. Eng. Sci. 2014, 3, 8-13.

46. Hanafin, S. Review of literature on the Delphi Technique; National Children's Office: Dublin, Ireland, 2004.

47. Ossola, d.R.L.P. Aspetti Metodologici e Statistiche del Delphi; Working Paper; Università dell'Insubria: Varese, Italy, 2003.

48. Mitroff, I.; Turoff, M. Philosophical and Methodological Foundations of Delphi. In The Delphi Method: Techniques and Applications; Linstone, H., Turoff, M., Eds.; Addison-Wesley Publishing Company: Boston, MA, USA, 2002.

49. Linstone, H.A.; Turoff, M. The Delphi Method: Techniques and Applications; Addison-Wesley: Boston, MA, USA, 1975.

50. Turoff, M. The Design of a Policy Delphi. Technol. Forecast. Soc. Chang. 1970, 2, 149-171. [CrossRef]

51. Hargadon, A.B.; Bechky, B.A. When collections of creatives become creative collectives: A field study of problem solving at work. Organ. Sci. 2006, 17, 484-500. [CrossRef]

52. Denis, J.-L.; Langley, A.; Rouleau, L. Strategizing in pluralistic contexts: Rethinking theoretical frames. Hum. Relat. 2007, 60, 179-205. [CrossRef]

53. Weick, K.E. Sensemaking in Organizations; Sage: Thousand Oaks, CA, USA, 1995.

54. Bowman, G. The Practice of Scenario planning: An Analysis of Inter- and Intra-organizational Strategizing. Br. J. Manag. 2016, 27, 77-96. [CrossRef]

55. Cunliffe, A.; Coupland, C. From hero to villain to hero: Making experience sensible through embodied narrative sensemaking. Hum. Relat. 2012, 65, 63-88. [CrossRef]

56. Czarniawska, B. A Theory of Organizing; Edward Elgar: Cheltenham, UK, 2008.

57. Scaratti, G.; Ivaldi, S.; Frassy, J. Networking and knotworking practices: Work integration as situated social process. J. Workplace Learn. 2017, 29, 2-23. [CrossRef]

58. Jarzabkowski, P.; Fenton, E. Strategizing and Organizing in Pluralistic Contexts. Long Range Plan. 2006, 39 , 631-648. [CrossRef]

(c) 2019 by the authors. Licensee MDPI, Basel, Switzerland. This article is an open access article distributed under the terms and conditions of the Creative Commons Attribution (CC BY) license (http://creativecommons.org/licenses/by/4.0/). 